Biochem Soc Trans. 2009 August ; 37(Pt 4): 805-810. doi:10.1042/BST0370805.

\title{
Angioplasticity in asthma
}

\author{
Kewal Asosingh ${ }^{1}$ and Serpil C. Erzurum ${ }^{1}$ \\ Department of Pathobiology, Lerner Research Institute, Cleveland Clinic, Cleveland, $\mathrm{OH} 44195$, \\ U.S.A., and Department of Pulmonary, Allergy and Critical Care Medicine, Lerner Research \\ Institute, Cleveland Clinic, Cleveland, OH 44195, U.S.A.
}

\section{Abstract}

Plasticity of the lung vasculature is intrinsically more complex than other organs due to the presence of two blood supply systems under different arterial pressures, the pulmonary and bronchial arterial systems. The bronchial and pulmonary circulations may both contribute to vascular remodelling in lungs after injury or inflammation. Vascular remodelling in the airway is a long recognized component in asthma. Growing numbers of reports suggest that a pro-angiogenic milieu is not a consequence of, but rather dictates the chronic inflammation of asthma. The fairly recent discovery of EPCs (endothelial progenitor cells) has enabled us to study the bone-marrow-derived cells that regulate lung vascular plasticity in asthma. This mini review provides a concise synopsis of our present knowledge about vascular plasticity in adult lungs, summarizes our current view of angioplasticity in asthma and highlights yet unresolved areas of potential interest.

\section{Keywords}

angioplasticity; asthma; endothelial progenitor cell (EPC); inflammation; lung; vascular endothelial growth factor (VEGF)

\section{Introduction}

\section{The human lung circulation}

The human lung circulation consists of two blood supply systems: a bronchial vasculature that is the systemic arterial blood supply providing oxygenated blood and nutrients to the lung tissue and a pulmonary vasculature carrying deoxygenated blood from the right ventricle to the lungs for oxygenation. Although more than $95 \%$ of the blood flow through the lungs is from the pulmonary circulation, experimental systems clearly show that the pulmonary circulation and bronchial circulation are both crucial for proper lung function. For example, remodelling of the small pulmonary arteries results in pulmonary hypertension, while remodelling of the bronchial vasculature is associated with chronic airway inflammatory diseases. The pulmonary artery branches run in parallel to bronchi and bronchioles and terminate in a diffuse capillary network surrounding the alveoli for gas exchange, to ultimately converge with pulmonary venules and pulmonary veins. The bronchial circulation arises directly from the aorta as bronchial arteries networking into two capillary plexus, one on each side of the airway smoothmuscle layer, the subepithelial plexus and adventitial plexus. These capillary networks form bronchial veins, which then also drain into the common pulmonary veins and return to the left atrium [1]. 


\section{Neovascularization, or new blood vessel formation}

Neovascularization, or new blood vessel formation, can occur by three major processes, namely vasculogenesis, angiogenesis and arteriogenesis. Vasculogenesis signifies de novo blood vessel formation during which primitive precursors migrate to vascularization sites, differentiate into endothelial cells and structurally become the newly formed blood vessel. Budding of new vessels from pre-existing ones is referred to as angiogenesis, while the increase in the luminal diameter of an artery to form a collateral is termed arteriogenesis [2,3].

New studies are revealing multiple functions and types of vascular stem and progenitor cells involved in neovascularization. Different biological assays and cell surface markers are used to define subsets of progenitors [4]. The EPC (en-dothelial progenitor cell) is one of the important participants in postnatal new blood vessel formation [5], and contributes to physiological and pathological neovascularization. EPCs are bone-marrow-derived cells and influence neovascularization through paracrine effects [6]. EPCs are enumerated by flow cytometric analysis using a combination of haemopoietic stem cells markers and endothelial cell antigens, such as CD34, CD133 and VEGF (vascular endothelial growth factor) receptor-2. Whether these bone-marrow-derived cells differentiate into true endothelial cells is a subject of debate [7,8]. However, culture of EPCs in vitro gives rise to CFU-ECs (colony-forming units of endothelial-like cells) or CFU-Hill colonies. CFU-ECs are heterogeneous colonies comprising proliferating progenitors [6] in the presence of T-cells [9]. The exact cellular composition of these colonies is currently unknown. Immunophenotypic analysis indicates low to intermediate expression of the progenitor cell markers CD34 and CD133. Cells are also positive for endothelial cell-like features such as uptake of acetylated low-density lipoprotein, lectin binding and expression of CD31, von Willebrand factor and vascular-endothelial cadherin. However, CFU-ECs also express the pan-haemopoietic marker CD45, myeloid marker CD33, CD11b and $\alpha$-smooth-muscle actin [10,11], thus they are not considered to be true endothelial cells. In contrast with the debate on the endothelial nature of the CFU-ECs derived from EPCs, a newly described endothelial progenitor, termed the ECFC (endothelial colony-forming cell), is considered to be a true endothelial stem cell. Little is known about ECFCs. These cells are rare in the circulation, most probably derived from the vascular wall, but can be expanded numerous times when needed as the building blocks of blood vessels (Figure 1). In this review, we provide a concise overview of our current knowledge about vascular remodelling in postnatal lungs, focusing on the EPCs in the process, and then present a current overview of angioplasticity in asthma highlighting the yet unresolved areas of potential interest.

\section{Plasticity of the lung vasculature}

Early studies (reviewed in $[1,12]$ ) indicate that the lung vasculature has considerable adaptation capacity. Leonardo da Vinci is generally recognized as the first one to report neovascularization in lung pathology [1]. Pulmonary artery obstruction in patients with chronic thromboembolic disease results in rapid (within 2-3 days) substantial expansion of the bronchial circulation [13]. Studies in adult dogs reveal that unilateral ligation of the pulmonary artery is associated with pre-capillary anastomoses between the pulmonary and bronchial circulation in order to supply the ischaemic lung regions [14]. It is the bronchial arteries that proliferate to anastomose with the pulmonary vasculature after obstruction of the pulmonary artery, and result in $\sim 10$ fold increase in the systemic blood flow through the lungs [15]. Whether this bronchial-topulmonary blood flow improves gas exchange has been suggested but is unlikely given the fact that the bronchial blood is already oxygenated [1]. On the other hand, angiogenesis induced either by hypoxia in rats [16] or pneumonectomy in adult animal models and in humans [17] results in alveolar proliferation, which indicates the concept of vascularization-directed alveolar growth. In support of this paradigm, inhibition of endothelial cell migration in neonatal rats causes impaired postnatal lung development, i.e. decreased alveolarization [18]. Targeted 
induction of apoptosis of lung endothelial cells in mice leads to a loss of alveoli numbers and leads to an emphysema-like pheno-type [19]. There is intriguing support for vascularizationdependent alveolarization in humans. In women, angiogenesis that occurs in the uterus over the menstrual cycle is closely associated with increases in pulmonary gas transfer, which occurs due to cyclic expansion and contraction of the pulmonary vascular capillary bed [20].

\section{Pro-angiogenic microenvironment and vascular remodelling in asthma}

Asthma is a chronic inflammatory disease pathologically defined by airway wall remodelling. Vascular remodelling of the airways including angiogenesis, vasodilation and microvascular leakage is one of most prominent and uniform findings in asthma. Angiogenesis is present in the earlyphases of adult asthma [21]. Compared with control subjects, the total number of vessels and vascular area in the airways are increased in adult asthmatics [22-24]. Analysis of the distribution of blood vessel sizes indicates an increase in the numbers of smaller vessels $(<25 \mu \mathrm{m})$ [25]. The increased numbers and sizes of vessels and vascular leakage contribute to thickening of the airway wall resulting in narrowing of the lumen [26].

Under homoeostatic circumstances, vascular quiescence is maintained by an equilibrium between endogenous angiogenic activators and inhibitors. In pathological angiogenesis, overproduction of angiogenic factors and/or down-regulation of inhibitors disturb this balance favouring pro-angiogenic factors and resulting in increased vascularization. Several proangiogenic mediators are expressed or up-regulated in asthmatic lungs (reviewed in [27]), but VEGF $\left(\right.$ VEGF $_{165}$ ) has been the most studied. Asthmatics have increased VEGF concentration in bronchoalveolar lavage fluid, and the levels correlate to blood vessel numbers in the asthmatic airway mucosa $[10,28]$. VEGF levels are also associated with other features of asthma such as basement membrane thickening [28], increased vascular leakage contributing to tissue oedema and airway hyperresponsiveness [29]. Compared with healthy controls, patients with asthma have increased amounts of VEGF and decreased amounts of the antiangiogenic factor endostatin in sputum [28,30,31]. VEGF levels in sputum are inversely associated with airflow parameters in children [32]. Furthermore, the sputum of children during an acute asthmatic attack contains elevated levels of VEGF, which are correlated to asthma severity [32]. Pro-angiogenic activity of bronchoalveolar lavage fluid from asthmatics is confirmed by quantitative in vitro angiogenic assays [33]. Animal models of allergen-induced airway hyperresponsiveness also have increased VEGF in bronchoalveolar lavage [29,34] and vascular remodelling [34]. In industrial chemical-induced asthma in mice, administration of the VEGF receptor tyrosine kinase inhibitors (SU5614 and SU1498) reduces the development of airway hyperresponsiveness and inflammation [29]. Definitive evidence of a causal role for VEGF $_{165}$ and angiogenesis in asthma comes from elegant studies by Elias and co-workers $[35,36]$ in which VEGF is overexpressed in airway epithelium of mice. These transgenic animals spontaneously develop airway inflammation, angiogenesis and an asthma-like phenotype [35]. Subsequent mechanistic studies in these mice show that nitric oxide synthesis is essential for the VEGF-mediated angiogenesis [36]. Altogether, the studies support a role for VEGF and angiogenesis in asthma.

Immunohistochemical analyses show that many cell types intrinsic to the asthmatic lung are capable of producing VEGF, including mast cells, eosinophils, macrophages and CD34+ cells in airway biopsies $[28,37,38]$. In addition, airway epithelium produces VEGF during rhinovirus-associated asthma exacerbations [39], or during dust mite allergen exposure [34]. Other structural cells such as fibroblasts [40] and airway smooth-muscle cells can probably also contribute to the high levels of VEGF in asthma [33]. 


\section{Inflammation promotes angiogenesis}

Angiogenesis and chronic inflammation are mutually supporting [41]. Inflammatory cells in asthma have the capacity to produce pro-angiogenic factors and induce angiogenesis. Eosinophils produce and release VEGF and other pro-angiogenic factors, including bFGF (basic fibroblast growth factor), IL-8 (interleukin-8), nerve growth factor, GM-CSF (granulocyte/macrophage colony-stimulating factor) and eotaxin [38,42]. Eosinophils directly induce endothelial cell proliferation in vitro, and neovascularization in rat aortic ring assays or in the chick embryo chorioallantoic membrane assay [43]. Mast cells produce high levels of VEGF and numerous other pro-angiogenic factors, such as FGF-2 (fibroblast growth factor 2 ), TGF $\beta$ (transforming growth factor- $\beta$ ), TNF $\alpha$ (tumour necrosis factor $\alpha$ ) and IL-8, and are the critical cells that promote angiogenesis in tumours $[42,44]$. Pro-inflammatory mediators such as TNF $\alpha$ [45] and nitric oxide [36] that are found at high levels in asthmatic lungs also promote angiogenesis, in part by induction of VEGF expression. Altogether, the inflammatory cells and mediators in asthma almost certainly combine to accelerate the angiogenic remodelling events in asthma. On the other hand, human and murine studies indicate an early onset of vascular remodelling in asthma, prior to inflammation onset [10].

\section{Airway angiogenesis in the genesis of airway inflammation}

Analysis of bronchial biopsies indicates an increased number of blood vessels and eosinophils in children with asthma, but also in atopic children without asthma when compared with healthy non-atopic individuals [46]. An increased vascular network is detected in the early phases of chronic adult asthma [21]; however, temporal analysis of the onset of angiogenesis and asthma is not possible in observational studies of humans. At the time of diagnosis, the airway inflammation and vascular remodelling are both well established. The ovalbumin mouse model of asthma has been used to study the sequential occurrence of these events [10]. In this model, mice are sensitized with intraperitoneal ovalbumin in adjuvant, followed weeks later by daily ovalbumin inhalation challenge over 8 days. A switch to a pro-angiogenic milieu takes place within the first $48 \mathrm{~h}$ after the first allergen inhalation challenge, well in advance of an influx of eosinophils, which reaches a peak on days 4-6 of allergen challenge. Rather, EPC mobilization from bone marrow and recruitment into the lung occurs within a few short hours after the first allergen challenge, which is followed quickly by vascular remodelling and neovascularization. Similar to previous studies in vascular injury and remodelling, EPCs apparently initiate the switch to a pro-angiogenic environment [10]. These findings raise the possibility that the angiogenic process is one of the driving forces that initiate and/or perpetuate asthmatic airway inflammation. Based upon the current paradigm of angiogenesis, EPCs release paracrine signals upon arrival at vascular sites, which alter the local microenvironment and promote neovascularization. Endothelial cells of newly formed blood vessels accelerate and amplify inflammation by facilitating the adhesion of circulating inflammatory cells and migration into the tissues. In the case of asthmatic inflammation, the EPC-mediated angiogenic switch is dependent on Th1/Th2 lymphocytes as indicated by allergen-specific adoptive transfer of Th1- and Th2-cells [10]. Transfer of either Th1 or Th2 cells into naive mice induces EPC mobilization and recruitment into the lungs, but new vessels do not form.

Neovascularization occurs only when both Th1 and Th2 cells are transferred together. Thus memory T-cells and their specific immunogenic products are required for the onset of angiogenic remodelling in asthma. In support of similar events in the genesis of human asthma, patients with asthma have greater than normal numbers of circulating EPCs, which exhibit increased proliferation potential and angiogenic activity [10]. 


\section{Future perspectives and conclusions}

Bronchial vascular remodelling is a universal finding in asthma. The mouse model of asthma identifies that the onset of neovascularization is before the recruitment of inflammatory cells into the lungs. In fact, several lines of evidence suggest that angiogenesis is an active component in the pathogenesis of inflammation in asthma. This raises several questions. Does bronchial angiogenesis promote airway inflammation? Does airway inflammation trigger angiogenesis? Or are inflammation and angiogenesis co-dependent? There is support for all three possibilities in the current literature (Figure 1). Do both vascular systems supplying the lung participate in the angiogenic remodelling? Or is the bronchial circulation primarily involved? Study of small rodents such as the mouse may be a limitation in answering this question as the murine lung vasculature and blood supply varies from the human. Only one report provides some evidence for the existence of both a pulmonary and bronchial circulation in mice [47]. Vascular corrosion casting of mouse lungs via the descending aorta followed by scanning electron microscopy analysis reveals the presence of a bronchial circulation in mice. However, interconnections between the two systems occur at the distal bronchial arteries and alveolar capillaries, and airway inflammation leads to an increase in bronchial perfusion of alveolar capillaries [47]. Nevertheless, observations of murine lungs provide useful information on the general plasticity of the pulmonary vascular bed.

The angiogenic switch has been shown to be an early event in asthma, but what are the triggers that disrupt the angiogenic equilibrium? VEGF alone is necessary but not sufficient to induce neovascularization [3]. What are the other (perhaps lung-specific) angiogenic factors involved? The functional role of EPCs in the angiogenic switch, their interactions with other cell types and how this may affect recruitment of inflammatory cells remain to be resolved. The angiogenic switch is dependent on both Th1 and Th2 cells in the murine asthma model, but it is yet unclear how T-cells contribute to the pro-angiogenic microenvironment. Insight into the immune mechanisms regulating lung vascular homoeostasis will be important for the design of more effective asthma therapies that may be based on anti-angiogenesis strategies to inhibit neovascularization and inflammation in the airway.

\section{Acknowledgments}

We thank David Schumick (Cleveland Clinic Center for Medical Art and Photography) for illustrations. We express our sincere apology to colleagues whose work could not be cited due to a restriction on the number of references.

\section{Funding}

This research was supported by the National Institutes of Health [grant numbers HL60917, HL69170, AI70649, HL081064, AI067816, HL04449, M01 RR018390 and UL1RR024989].

\section{Abbreviations used}

$\begin{array}{ll}\text { CFU } & \text { colony-forming units } \\ \text { EC } & \text { endothelial-like cell } \\ \text { ECFC } & \text { endothelial colony-forming cell } \\ \text { EPC } & \text { endothelial progenitor cell } \\ \text { IL-8 } & \text { interleukin- } 8 \\ \text { TNF } \alpha & \text { tumour necrosis factor } \alpha \\ \text { VEGF } & \text { vascular endothelial growth factor }\end{array}$




\section{References}

1. Charan NB, Baile EM, Pare PD. Bronchial vascular congestion and angiogenesis. Eur Respir J 1997;10:1173-1180. [PubMed: 9163664]

2. Carmeliet P. Angiogenesis in health and disease. Nat Med 2003;9:653-660. [PubMed: 12778163]

3. Semenza GL. Vasculogenesis, angiogenesis, and arteriogenesis: mechanisms of blood vessel formation and remodeling. J Cell Biochem 2007;102:840-847. [PubMed: 17891779]

4. Prater DN, Case J, Ingram DA, Yoder MC. Working hypothesis to redefine endothelial progenitor cells. Leukemia 2007;21:1141-1149. [PubMed: 17392816]

5. Asahara T, Murohara T, Sullivan A, Silver M, van der Zee R, Li T, Witzenbichler B, Schatteman G, Isner JM. Isolation of putative progenitor endothelial cells for angiogenesis. Science 1997;275:964967. [PubMed: 9020076]

6. Yoder MC, Mead LE, Prater D, Krier TR, Mroueh KN, Li F, Krasich R, Temm CJ, Prchal JT, Ingram DA. Redefining endothelial progenitor cells via clonal analysis and hematopoietic stem/progenitor cell principals. Blood 2007;109:1801-1809. [PubMed: 17053059]

7. Purhonen S, Palm J, Rossi D, Kaskenpaa N, Rajantie I, Yla-Herttuala S, Alitalo K, Weissman IL, Salven P. Bone marrow-derived circulating endothelial precursors do not contribute to vascular endothelium and are not needed for tumor growth. Proc Natl Acad Sci USA 2008;105:6620-6625. [PubMed: 18443294]

8. Kerbel RS, Benezra R, Lyden DC, Hattori K, Heissig B, Nolan DJ, Mittal V, Shaked Y, Dias S, Bertolini F, Rafii S. Endothelial progenitor cells are cellular hubs essential for neoangiogenesis of certain aggressive adenocarcinomas and metastatic transition but not adenomas. Proc Natl Acad Sci USA 2008;105:E54. [PubMed: 18715995]

9. van Beem RT, Noort WA, Voermans C, Kleijer M, ten Brinke A, van Ham SM, van der Schoot CE, Zwaginga JJ. The presence of activated CD4+ T cells is essential for the formation of colony-forming unit-endothelial cells by CD14+ cells. J Immunol 2008;180:5141-5148. [PubMed: 18354240]

10. Asosingh K, Swaidani S, Aronica M, Erzurum SC. Th1- and Th2-dependent endothelial progenitor cell recruitment and angiogenic switch in asthma. J Immunol 2007;178:6482-6494. [PubMed: 17475878]

11. Asosingh K, Aldred MA, Vasanji A, Drazba J, Sharp J, Farver C, Comhair SA, Xu W, Licina L, Huang L, et al. Circulating angiogenic precursors in idiopathic pulmonary arterial hypertension. Am J Pathol 2008;172:615-627. [PubMed: 18258847]

12. Bhattacharya J. Lung neovascularization: a tale of two circulations. Am J Physiol Lung Cell Mol Physiol 2008;294:L417-L418. [PubMed: 18192593]

13. Williams MH Jr, Towbin EJ. Magnitude and time of development of the collateral circulation to the lung after occlusion of the left pulmonary artery. Circ Res 1955;3:422-424. [PubMed: 14390726]

14. Liebow AA, Hales MR, Bloomer WE, Harrison W, Lindskog GE. Studies on the lung after ligation of the pulmonary artery II: anatomical changes. Am J Pathol 1950;26:177-195. [PubMed: 15406250]

15. Ley S, Kreitner KF, Morgenstern I, Thelen M, Kauczor HU. Bronchopulmonary shunts in patients with chronic thromboembolic pulmonary hypertension: evaluation with helical CT and MR imaging. AJR Am J Roentgenol 2002;179:1209-1215. [PubMed: 12388501]

16. Hyvelin JM, Howell K, Nichol A, Costello CM, Preston RJ, McLoughlin P. Inhibition of Rho-kinase attenuates hypoxia-induced angiogenesis in the pulmonary circulation. Circ Res 2005;97:185-191. [PubMed: 15961717]

17. Hsia CC. Signals and mechanisms of compensatory lung growth. J Appl Physiol 2004;97:1992-1998. [PubMed: 15475557]

18. DeLisser HM, Helmke BP, Cao G, Egan PM, Taichman D, Fehrenbach M, Zaman A, Cui Z, Mohan GS, Baldwin HS, et al. Loss of PECAM-1 function impairs alveolarization. J Biol Chem 2006;281:8724-8731. [PubMed: 16377626]

19. Giordano RJ, Lahdenranta J, Zhen L, Chukwueke U, Petrache I, Langley RR, Fidler IJ, Pasqualini R, Tuder RM, Arap W. Targeted induction of lung endothelial cell apoptosis causes emphysema-like changes in the mouse. J Biol Chem 2008;283:29447-29460. [PubMed: 18718906] 
20. Farha S, Asosingh K, Laskowski D, Licina L, Sekiguchi H, Losordo DW, Dweik RA, Wiedemann HP, Erzurum SC. Pulmonary gas transfer related to markers of angiogenesis during the menstrual cycle. J Appl Physiol 2007;103:1789-1795. [PubMed: 17717117]

21. Hashimoto M, Tanaka H, Abe S. Quantitative analysis of bronchial wall vascularity in the medium and small airways of patients with asthma and COPD. Chest 2005;127:965-972. [PubMed: 15764783]

22. Li X, Wilson JW. Increased vascularity of the bronchial mucosa in mild asthma. Am J Respir Crit Care Med 1997;156:229-233. [PubMed: 9230753]

23. Salvato G. Quantitative and morphological analysis of the vascular bed in bronchial biopsy specimens from asthmatic and non-asthmatic subjects. Thorax 2001;56:902-906. [PubMed: 11713351]

24. Dunnill MS. The pathology of asthma, with special reference to changes in the bronchial mucosa. J Clin Pathol 1960;13:27-33. [PubMed: 13818688]

25. Feltis BN, Wignarajah D, Zheng L, Ward C, Reid D, Harding R, Walters EH. Increased vascular endothelial growth factor and receptors: relationship to angiogenesis in asthma. Am J Respir Crit Care Med 2006;173:1201-1207. [PubMed: 16528018]

26. Moreno RH, Hogg JC, Pare PD. Mechanics of airway narrowing. Am Rev Respir Dis 1986;133:11711180. [PubMed: 3717766]

27. Chetta A, Zanini A, Olivieri D. Therapeutic approach to vascular remodelling in asthma. Pulm Pharmacol Ther 2007;20:1-8. [PubMed: 16338153]

28. Chetta A, Zanini A, Foresi A, D’Ippolito R, Tipa A, Castagnaro A, Baraldo S, Neri M, Saetta M, Olivieri D. Vascular endothelial growth factor up-regulation and bronchial wall remodelling in asthma. Clin Exp Allergy 2005;35:1437-1442. [PubMed: 16297139]

29. Lee YC, Kwak YG, Song CH. Contribution of vascular endothelial growth factor to airway hyperresponsiveness and inflammation in a murine model of toluene diisocyanate-induced asthma. J Immunol 2002;168:3595-3600. [PubMed: 11907124]

30. Asai K, Kanazawa H, Otani K, Shiraishi S, Hirata K, Yoshikawa J. Imbalance between vascular endothelial growth factor and endostatin levels in induced sputum from asthmatic subjects. J Allergy Clin Immunol 2002;110:571-575. [PubMed: 12373263]

31. O’Reilly MS, Boehm T, Shing Y, Fukai N, Vasios G, Lane WS, Flynn E, Birkhead JR, Olsen BR, Folkman J. Endostatin: an endogenous inhibitor of angiogenesis and tumor growth. Cell 1997;88:277-285. [PubMed: 9008168]

32. Abdel-Rahman AM, el-Sahrigy SA, Bakr SI. A comparative study of two angiogenic factors: vascular endothelial growth factor and angiogenin in induced sputum from asthmatic children in acute attack. Chest 2006;129:266-271. [PubMed: 16478840]

33. Simcock DE, Kanabar V, Clarke GW, O'Connor BJ, Lee TH, Hirst SJ. Proangiogenic activity in bronchoalveolar lavage fluid from patients with asthma. Am J Respir Crit Care Med 2007;176:146153. [PubMed: 17463417]

34. Avdalovic MV, Putney LF, Schelegle ES, Miller L, Usachenko JL, Tyler NK, Plopper CG, Gershwin LJ, Hyde DM. Vascular remodeling is airway generation-specific in a primate model of chronic asthma. Am J Respir Crit Care Med 2006;174:1069-1076. [PubMed: 16931639]

35. Lee CG, Link H, Baluk P, Homer RJ, Chapoval S, Bhandari V, Kang MJ, Cohn L, Kim YK, McDonald DM, Elias JA. Vascular endothelial growth factor (VEGF) induces remodeling and enhances Th2mediated sensitization and inflammation in the lung. Nat Med 2004;10:1095-1103. [PubMed: 15378055]

36. Bhandari V, Choo-Wing R, Chapoval SP, Lee CG, Tang C, Kim YK, Ma B, Baluk P, Lin MI, McDonald DM, et al. Essential role of nitric oxide in VEGF-induced, asthma-like angiogenic, inflammatory, mucus, and physiologic responses in the lung. Proc Natl Acad Sci USA 2006;103:11021-11026. [PubMed: 16832062]

37. Hoshino M, Takahashi M, Aoike N. Expression of vascular endothelial growth factor, basic fibroblast growth factor, and angiogenin immunoreactivity in asthmatic airways and its relationship to angiogenesis. J Allergy Clin Immunol 2001;107:295-301. [PubMed: 11174196]

38. Nissim Ben Efraim AH, Levi-Schaffer F. Tissue remodeling and angiogenesis in asthma: the role of the eosinophil. Ther Adv Respir Dis 2008;2:163-171. [PubMed: 19124368] 
39. Psarras S, Volonaki E, Skevaki CL, Xatzipsalti M, Bossios A, Pratsinis H, Tsigkos S, Gourgiotis D, Constantopoulos AG, Papapetropoulos A, et al. Vascular endothelial growth factor-mediated induction of angiogenesis by human rhinoviruses. J Allergy Clin Immunol 2006;117:291-297. [PubMed: 16461129]

40. Sugiura H, Liu X, Duan F, Kawasaki S, Togo S, Kamio K, Wang XQ, Mao L, Ahn Y, Ertl RF, et al. Cultured lung fibroblasts from ovalbumin-challenged 'asthmatic' mice differ functionally from normal. Am J Respir Cell Mol Biol 2007;37:424-430. [PubMed: 17575074]

41. Jackson JR, Seed MP, Kircher CH, Willoughby DA, Winkler JD. The codependence of angiogenesis and chronic inflammation. FASEB J 1997;11:457-465. [PubMed: 9194526]

42. Puxeddu I, Ribatti D, Crivellato E, Levi-Schaffer F. Mast cells and eosinophils: a novel link between inflammation and angiogenesis in allergic diseases. J Allergy Clin Immunol 2005;116:531-536. [PubMed: 16159620]

43. Puxeddu I, Alian A, Piliponsky AM, Ribatti D, Panet A, Levi-Schaffer F. Human peripheral blood eosinophils induce angiogenesis. Int J Biochem Cell Biol 2005;37:628-636. [PubMed: 15618019]

44. Ribatti D, Crivellato E, Roccaro AM, Ria R, Vacca A. Mast cell contribution to angiogenesis related to tumour progression. Clin Exp Allergy 2004;34:1660-1664. [PubMed: 15544587]

45. Berry M, Brightling C, Pavord I, Wardlaw A. TNF- $\alpha$ in asthma. Curr Opin Pharmacol 2007;7:279282. [PubMed: 17475560]

46. Barbato A, Turato G, Baraldo S, Bazzan E, Calabrese F, Panizzolo C, Zanin ME, Zuin R, Maestrelli P, Fabbri LM, Saetta M. Epithelial damage and angiogenesis in the airways of children with asthma. Am J Respir Crit Care Med 2006;174:975-981. [PubMed: 16917118]

47. Ravnic DJ, Konerding MA, Pratt JP, Wolloscheck T, Huss HT, Mentzer SJ. The murine bronchopulmonary microcirculation in hapten-induced inflammation. J Thorac Cardiovasc Surg 2007;133:97-103. [PubMed: 17198790] 


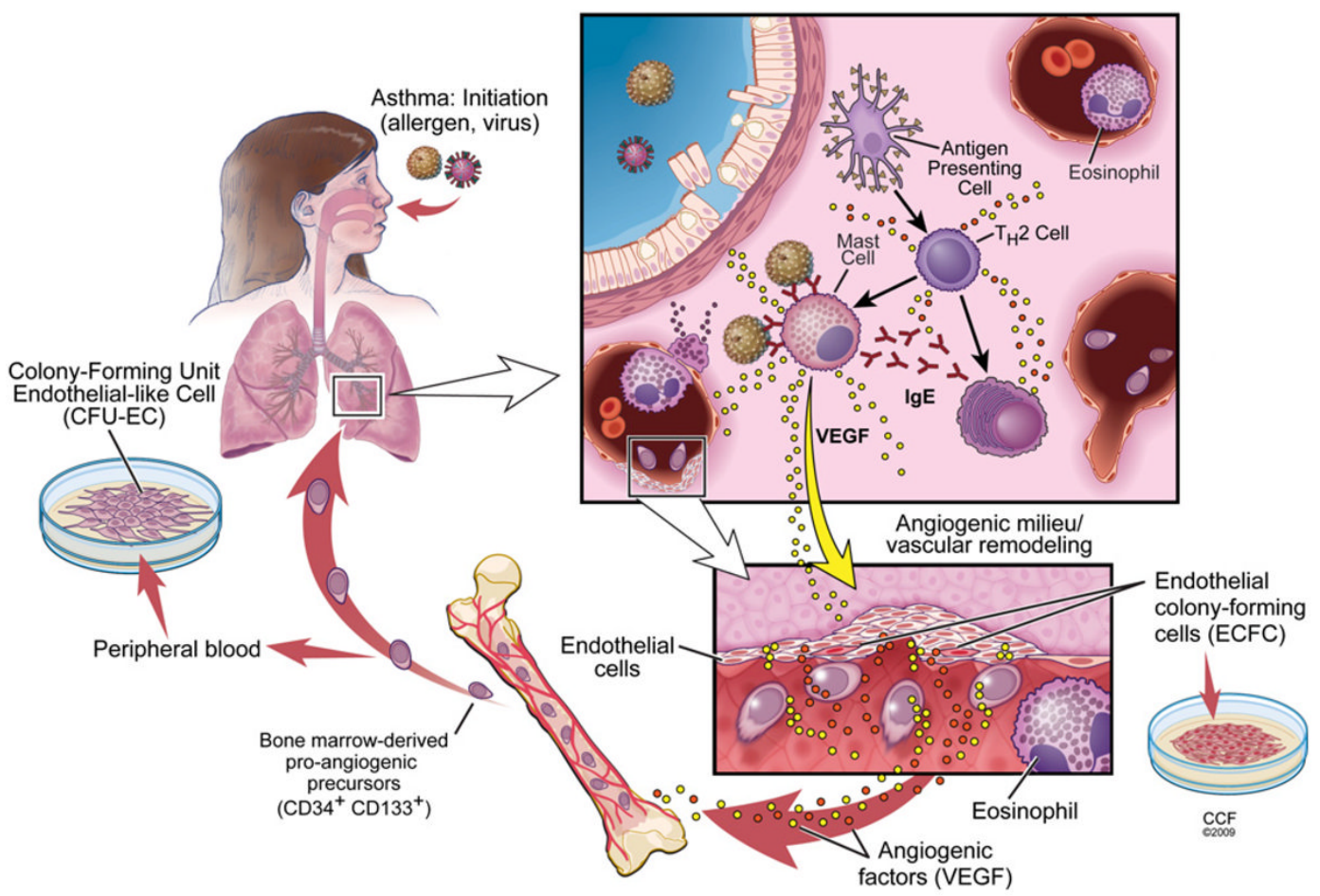

Figure 1. Neovascularization in asthma

The pathophysiology of asthma is related to allergy, and/or infections with respiratory viruses. Inhalational exposures with allergens, or virus infections, trigger asthma exacerbations. In the case of an allergen, antigen-presenting cells capture the allergen and trigger immune responses skewed towards Th 2 cells. Th2 cells induce allergen-specific IgE production by B-cells, which bind to the surface of mast cells. Mast cells degranulate upon their subsequent encounter with allergen(s). Mast cell and T-cell derived products induce a cascade reaction involving structural vascular cells and airway epithelial cells that result in the recruitment of eosinophils, typical effector cells in asthma. Damage to structural lung cells (epithelial cells, endothelial cells and smooth-muscle cells) is caused by eosinophil-derived products, which leads to airway hyperresponsiveness and airway remodelling. VEGF (and other yet unknown angiogenic triggers) may be released by activation of epithelial and mast cells and initiates the mobilization of EPCs from the bone marrow into the peripheral circulation. Homing signals recruit EPCs into the lungs. EPCs switch the local environment from vascular quiescence to a pro-angiogenic state. Mediators released by EPCs either directly or indirectly via interactions with vascular cells in the newly formed blood vessels facilitate the recruitment and activation of proinflammatory cells such as eosinophils. Reprinted with permission, Cleveland Clinic Center for Medical Art \& Photography (C2009. All Rights Reserved. 